\title{
Socio-Demographical Factors on Academic Redshirting as Perceived by School-going Adolescents with Special Needs
}

\author{
Kehinde Clement Lawrence \\ Department of Educational Psychology and Special Education, \\ University of Zululand, South Africa
}

DOI: https://doi.org/10.36941/ajis-2020-0082

Abstract

This study investigated some socio-demographical on academic redshirting as perceived by school-going adolescents with special needs in Ibadan, Nigeria. As a quantitative study, the principles of descriptive design of correlational type was adopted. The results revealed that academic redshirting had significant positive correlation with age, and negatively but significant with interest in schooling, parental involvement and community support. It was concluded that early enrolment of children with special needs is critical to initiate adolescents with special needs' interest in schooling and sense of belonging.

Keywords: academic redshirting; age, community support; interest in schooling; parental involvement

\section{Introduction}

The practice of academic redshirting in the Africa communities has continued to rob many school age-children with special needs their right to inclusive education due to their condition of needs. Many parents and caregivers often time deliberately marginalize and exclude these children from participating in free and compulsory education. This practice is still prevalent in most African counties particularly in Nigeria notwithstanding several global policies and awareness on Education for All, Integrated or Inclusive Education and No Child Left Behind (NCLB) among others. Commonly, all these polices focus on ensuring that the conventional schools accommodate all children irrespective of their race, gender, social status, religion, physical, intellectual, linguistic, emotional or other conditions. That is to say, all children have equal right to be enrolled and participate in the regular school, while government across all levels, educational stakeholders including; the child, parents, teachers and the society must all be involved.

Recently, the United Nations Children's Fund (UNICEF, 2015), stated that not less than 93 million school age children with special needs in Africa were not in school, out of about 600 million people with special needs in the world as reported by United Nations Economic Commission of Africa (UNECA, 2016). While the developing countries recorded larger proportion of about 400 million, there are still some disparities in the exert figures of children with special needs in Africa, partly because of lack of adequate data base, low research interest in the excluded individual, low consideration given to the affected children, overprotection by parents and family caregivers and stigmatization. According to Umoh (2014), the increase rate of children with special needs in African is alarming due to continues terrorism attacks, developmental delay, outbreak of diseases, ignorance and poverty that immersed the continent, which mostly prevent these children with exception of very 
small proportion in special schools, and far fewer who are benefiting from inclusive education.

According to UNICEF (2011), about 10 and 15 percent of children in Africa grow up with one special needs or the other, while school enrolment of such children is much delayed than other children without special needs. In the same vain, it was observed that children with special needs who were privileged to be enrolled early, did so not at an appropriate school age, hence, aiding academic or educational redshirting. The only single reason for this delay could be due to wrong orientation or belief of Africa society, that these group of children may not be able to acquire the needed human capital skills necessary to enable them earn high income, and also, the probability of children with special needs to dropout or leave school earlier with lesser qualifications than their counterparts without special needs (Obiora, 2014). Academic redshirting was defined by Early Childhood Quarterly Research, (ECQR, 2009) as the practice of deliberate postponing the enrolment of age-eligible children into regular school in order to allow extra time due to their conditions of needs raging from social, emotional, developmental, intellectual, or physical difficulties. Also, Katz (2000), conceptualized academic redshirting as parental way of making children with special needs grow older the following year before enrolling them into regular school so as to give them academic edge. This practice is more in athletic college whereby a child is held back for a year to develop physical strength and improve athletic skills.

Additionally, Holbrook (2015), advocated that redshirting could be a strategy for giving children with special needs an extra year to mature before schooling. This prejudice however, has be preventing these group of children from benefiting from a stimulating school environment. This is why Elder and Lubotsky (2016), allude that children with needs who are redshirted miss out of early childhood interaction with peers and are at risk of being bullied. While ordinarily children with special needs are susceptible to high risk of physical abuse, further delay in their school integration where care and support by teachers and peers poses higher risk of being sexually abused, depressed and suicidal thought. Therefore, it is the concern of this study to investigate some sociodemographical factors (interest in schooling, parental involvement, community support, age and gender) as perceived by school-going adolescents with special needs that could be responsible for academic redshirting.

\section{Related literature}

\subsection{Interest in schooling}

Interest in schooling, parental involvement, community support, age and gender are important resources for reducing practice of academic redshirting of children with special needs for progressive implementation of inclusive education. Interest in schooling, just like academic interest is crucial towards school enrolment of children with special needs. In that, it is the personal motivation gear towards acquiring knowledge and sustained learning attention (Hidi \& Renninger, 2006). Interest in schooling has been used interchangeably with academic persistence and engagement, as well as learning motivation (Sansone \& Smith, 2000; Hidi, Renninger \& Krapp, 2004). Interest in school is either developed or generated through innate or situation/environment forces (Ainley, Hidi, \& Berndorff, 2002; Hidi \& Renninger, 2006). In classical learning theories of skinner, interest in schooling is rooted in cognition-based interest, with claim that children get excited with activities that are rewarding (Lawrence, 2019). Seen other children going to school, doing home-work, wearing school uniform, sometimes stimulate children with special needs to aspire to go school which is usually being discouraged at times by many parents that practice academic redshirting. Barron (2007) advocated that learners' interests, abilities, and experiences are not often factored into children enrolment policies, this often time encourages continuous practice of academic redshirting. Lee and Durksen (2018), identified satisfaction excitement and enjoyment as components of interest in schooling. Although, there is paucity of literature on the relationship of interest in school and academic redshirting, thus, it is expected that interest in school of children with special needs would 
determine their academic redshirting.

\subsection{Parental involvement}

Parental involvement is another factor that could play a critical role in reducing practice of academic redshirting of children with special needs as projected in this study. For children with special needs to be enrolled in school, the full support/involvement of parents cannot be undermined. In this study, parental involvement is defined as efforts of a father, mother or legal guidance to enroll a child or children with special needs to conventional school at appropriate. Researches have established that parental involvement influenced child's school enrolment (Dixon, 2008; Constantino, 2003; Noel \& Newman, 2003). Children with special needs whose parents are involved in their education are likely going to be academically successful than children whose parents were less involved. Also, past studies have demonstrated that early parental involvement reduces dropout and truancy (Cook, Dodge, Gifford \& Schulting, 2017; Osisanya, Oyewumi \& Adigun, 2015). This was confirmed by Gottfredson and Hussong (2011), who found out that parental involvement influence school enrolment and transition to high school, and reduced risk of dropout. Also, another study established that parental involvement correlated with learners' interest in schooling (Fite, Cooley, Williford, Frazer \& DiPierro, 2014). Going by these past studies, to the best knowledge of this researcher, there is no study that has examined the relationship between parental involvement and academic redshirting, except for those that considered related constructs such as parental involvement and academic performance, educational attainment expectation, academic sell-efficacy and the (Hill \& Taylor, 2004; Koonce \& Harper, 2005; Brandon, 2007; Koskel, 2014). Thus, it is hypothesized that parental involvement would influence the practice of academic redshirting.

\subsection{Community support}

Community support otherwise refers to as social support could also predict the practice of academic redshirting of children with special needs. Community support in this study is the assistance of needed help provided by member (s) of the society to children with special needs in other to encourage their educational participation or educational integration. In the view of Cryder, Kilmer, Tedeschi, and Calhoun (2016), community support aids adjustment of children with special needs by encouraging their expression of feelings and providing nonjudgmental support of thoughts and assisting with needed instrumental for expression of schooling potentials. In the same vain, Vigil and Geary (2008), adjudged that community support is among the strongest predictors of mental health and physical functioning of children with special needs. Perceived community support has generally been found to relate more positively with students' academic outcomes (Cryder, Kilmer, Tedeschi, \& Calhoun, 2006; Pina et al., 2008; Borja \& Callahan, 2008). Researchers have found out that children living with special needs continue to be the most excluded from schooling because of lack of community support available to them, while other children with no special needs benefited more from schooling and enjoy community support (UNICEF, 2012). Except for a few of children living with special needs from high social economic background who are in school, small proportion of them benefited from inclusive education (Bordignon \& Lam, 2004). Although, there is considerable debate about the potential interplay of community support and special needs individuals, but relatively little is known empirically about community support and academic redshirting. Therefore, it surfaces to say that when community support is available to children with special needs, practice of academic redshirting would reduce.

\subsection{Age}

Vital to this study is age of children with special needs. Age has been described as the length of time a person has existed. Age is one factor that is considered when a child is about to enter into regular 
school. Age is a trend in academic redshirting with direct relationship effects (Sarosky, 2009). A research regarding age and academic redshirting emphasises that, it is more beneficial to delay an age eligible child's enrolment into regular by a year since it is believed that academic achievement is higher among older students (Lincove \& Painter, 2006). However, Age of Entry (2007) argued that the age of children enrolment in regular school should not be a major determinant of their school achievement. It was further contended that age-of-entry has no effect on social development. As important as age is in determining school entry, child's readiness in terms of the cognitive, psychical, emotion and social development are critical to children with disabilities' practice of redshirting. Maybe this is why one of the fathers of developmental psychologists Jean Piaget advocated that certain learning may not take place if a child has not reach a unique qualitative age of life. Equally, in an analytical study conducted by Education Commission of the States (2013), the study found that no universal age of entry into regular school especially for children with special needs.

According to Piaget in Graue and DiPerna (2000), delayed entry allows students extra time to reach a developmental stage at which they would be ready to be academically successful in school. Importantly, the argument in this study is basically individual with special needs who have attained entry age but was delayed purposely because of either psychical or intellectual disabilities. Although, Graue and DiPerna (2000) argued that readiness requires patience and cannot be forced. Smith (2016), noted that when a child is enrolled regardless of disabilities, gives cognitive growth opportunities through social interaction with their same-aged peers for such child. In addition, Diamond, Reagan, Bandyk (200o), emphasis that academic redshirting raises the average age of school enrolment which could lead to alteration rate. The study of Oshima and Domaleski (2016), found that the larger predictor of redshirting and academic achievement was age. Owing to the above, it could be hypothesized that there would be a relationship between age and academic redshirting.

\subsection{Gender}

In this study, gender is the last factor that is taken into consideration in the practice of academic redshirting of children with special needs. Some researchers have taken time out to investigate the impact of gender on academic redshirting. In a recent research of Capadona (2019), who sampled 109 academically-redshirted males' middle school level learners and determine their behaviour and academic performance through a quantitative research design, the finding of the research revealed no significant correlation between male who are academically redshirted academic performance and behavioural success. According to Smith (2016), academic success is found to be connected to gender differences. He further found that girls tend to benefit more in terms of school entry with greater readiness for learning than boys who are of the same age. The implication of this is that, boys with special needs would be academically redshirted than their girls' counterpart. Similarly, research conducted by Databank Child Trends (2014), revealed that gender has direct link with academic redshirting of children with special needs. In reviewing a longitudinal study carried out by Huang and Invernizzi (2013) on 405 students with low-performing and high-poverty in Virginia's public schools. It was found that there was no significant different between academically redshirted students' based on gender, ethnicity, economic and disability status. Although, it has been generically proven that boys mature slower than girls (Graue \& DiPerna, 2000; Ede, 2004; Raffaele, Kim, Ferron \& Woods, 2014). Hence, the concern of this current study to further investigate the significant role of gender in the Nigeria context on the practice of academic redshirting.

\section{Theoretical Framework}

This study was anchored on maturational-developmental theory of Arnold Gesell. The theory believed that individual child's development timing varies and sequence of stages are largely unaltered. That is, there is uniqueness in the pattern of child development which differ by gender 
(Fleischman, 2007). Also, it was also established that child development is influenced by both internal and external factors like parenting styles, early experiences with peers and adults, environment, cultural influences, family background and health conditions and that the only important factor that can affect the development of a child is the programmes generic makeup (Gesell Institute of Human Development, n.d., p. 1). The theory further emphasised emotional maturation as a major factor to be considered in school entry (Thelen \& Adolph, 1992 in Capadona, 2018). Equally, the importance of inclusive education regardless of chronological age was stressed as it can be a poor indicator of school readiness and academic success. It is in line with this theory that three research objectives were drawn guided by three questions.

\section{Objective of the Study}

This study investigated some socio-demographical factors on academic redshirting as perceived by school-going adolescents with special needs in Ibadan, Nigeria. Specifically the study:

1. Examined the pattern of relationship that exist among interest in schooling, parental involvement, community support, age, gender academic redshirting of adolescents with special needs.

2. Assessed the combined contribution of interest in schooling, parental involvement, community support, age and gender on academic redshirting of adolescents with special needs

3. Determined the relative contribution of interest in schooling, parental involvement, community support, age and gender on academic redshirting of adolescents with special needs.

4. Established the difference between in academic redshirting of adolescents with special needs base on their gender

\section{Research Questions}

1. To what extent was interest in schooling, parental involvement, community support, age, and gender relate with academic redshirting of adolescents with special needs?

2. Was there any significant contributing effect of interest in schooling, parental involvement, community support, age and gender on academic redshirting of adolescents with special needs?

3. To what extent was each of these socio-demographical factors (interest in schooling, parental involvement, community support, age and gender) predicts academic redshirting of adolescents with special needs?

4. Was there any significant difference in the academic redshirting of adolescents with special needs base on their gender?

\section{Methodology}

\subsection{Study design}

The study adopted the quantitative research approach using the principle of descriptive design of correlational type with the population of this study consists of all the special need adolescents in Ibadan metropolis, who have enrolled in the public primary school in Ibadan, Oyo-state. Ibadan is one of the cities that has the highest number of special need school, so it is expected that the adolescents will adequately represent other special need children in Nigeria. Adopting the purposive sampling procedure, one hundred and fifty (150) participants within the ages of 14 and 18 years who are hard of hearing, visually impaired and physically challenged were selected from two public special school in Ibadan. The data collected were analysed using Pearson Product Moment Correlation, 
Multiple Regression and independent t-test analysis statistical tools to answer the four research questions asked in the study.

\subsection{Research Instruments}

Validated instruments were used for data collection, which contained academic redshirting scale developed by the researcher consisting of an 8-item with response format ranging from strongly agree (4) to strongly disagree (1). The psychometric properties of the scale reported .6o1 Cronbach Alpha value. Parental involvement scale by Hoover-Dempsey, Walker, Jones, and Reed (2002) was adapted. The 10 item scale was a four-point likert response format with options ranging from strongly agree coded as (4) to strongly disagree coded as (1). The internal consistency of the scale reported a reliability alpha coefficient of 0.870 . Similarly, the multidimensional social support scale comprised 8-item which measured the perceptions of the participants on community support was revalidated by Zimet, Dahlem, Zimet and Farley (2016) with Cronbach Alpha value of .701 was adapted for the study. Response format was also modified to four point likert of strongly agree (4) to strongly disagree (1). While interest in schooling scale developed by Mitchell (1993) was adapted. The 10-item scale was modified by Adeyemo (2009) to suit the Nigerian environment with response format ranging from strongly agree (4) to strongly disagree (1). Internal consistency using Cronbach alpha reliability method also accounted for 0.79 value.

\subsection{Ethical Considerations}

The study complied with all ethics of research. This was done by allowing voluntary participation of the participants, guaranteed the confidentiality of all the information provided and ascertained that no harm during the administration of the questionnaires was done to the participants. Pledged that the information supplied will only be used for research purposes only.

\section{Results}

Research Question I: To what extent was interest in schooling, parental involvement, community support, age, and gender relate with academic redshirting of adolescents with special needs?

Table 1: Summary of Test of significant Correlations of socio-demographical factors of academic redshirting

\begin{tabular}{|c|c|c|c|c|c|c|c|c|}
\hline Variable & Mean & SD & 1 & 2 & 3 & 4 & 5 & 6 \\
\hline Academic redshirting & $19 \cdot 58$ & 5.33 & 1 & & & & & \\
\hline Gender & 1.54 & .50 & .086 & 1 & & & & \\
\hline Age & 5.64 & 1.71 & $.425^{* *}$ & $.323^{* *}$ & 1 & & & \\
\hline Interest in schooling & 30.80 & 4.86 & $-.776^{* *}$ & $-.311^{* *}$ & .059 & 1 & & \\
\hline Community support & 20.68 & 2.95 & $-.662^{* *}$ & $-.155^{*}$ & .053 & $-.778_{* *}^{* *}$ & 1 & \\
\hline Parental involvement & 24.92 & 2.68 & $-.709^{* *}$ &,- 058 & $.168^{* *}$ & $-.573^{* *}$ & $.520^{* *}$ & 1 \\
\hline
\end{tabular}

Table 1 shows that academic redshirting related significantly with interest in schooling, community support, parental involvement and age. Importantly, age was the only factor in this study that related passively and significantly with academic redshirting $(\mathrm{r}=0.425, \mathrm{p}<0.05)$. While other factors; interest in schooling, community support, parental involvement and gender related negatively and significantly with academic redshirting in the following order interest in schooling $(\mathrm{r}=-0.776$, $\mathrm{p}<0.05)$, community support, $(\mathrm{r}=-0.662, \mathrm{p}<0.05)$ and parental involvement $(\mathrm{r}=-0.709, \mathrm{p}<0.05)$. However, no significant relationship was found with gender and academic redshirting $(r=0.086, p>$ 
0.05).

Research Question II: Was there any significant contributing effect of interest in schooling, parental involvement, community support, age and gender on academic redshirting of adolescents with special needs?

Table 2: Multiple Regression Analysis showing joint effect of the independent variables on academic redshirting

\begin{tabular}{|c|c|c|c|c|c|c|}
\hline & $\begin{array}{l}.597 \\
\text { hange }=0.356 \\
\text { sted } R^{2}=.34 \\
\text { dard Error o }\end{array}$ & te $=4.31741$ & & & & \\
\hline & & Sum of Squares & Df & Mean Square & $\mathrm{F}$ & Sig. \\
\hline & Regression & 2512.732 & 5 & 502.546 & 26.961 & $.000^{\mathrm{a}}$ \\
\hline 1 & Residual & 4548.168 & 144 & 18.640 & & \\
\hline & Total & 7060.900 & 149 & & & \\
\hline
\end{tabular}

In response to the second research question, table 2 revealed the combined contribution interest in schooling, community support, parental involvement, age and gender) on academic redshirting. The result yielded a coefficient of multiple regressions $\mathrm{R}=0.597$ and multiple $\mathrm{R}$-square $=0.343$. This indicated that all the five factors combined accounted for $34.3 \%$ (Adj.R2 $=.343$ ) variance in the prediction of academic redshirting. The other factors accounting for $62.7 \%$ variance in the prediction of academic redshirting was beyond the scope of this study. The ANOVA result from the regression analysis showed that there was a significant contribution of the independent variables on the academic redshirting, $\mathrm{F}(5,244)=(26.961, \mathrm{p}<0.001)$.

Research Question III: To what extent was each of these socio-demographical factors (interest in schooling, parental involvement, community support, age and gender) predict academic redshirting of adolescents with special needs?

Table 3: Relative contribution of the socio-demographical factors to the prediction of academic redshirting as perceived by adolescents with special needs

\begin{tabular}{lccccc}
\hline \multirow{2}{*}{ Model } & \multicolumn{2}{c}{ Unstandardized Coefficients } & Standardized Coefficients & \multirow{2}{*}{ T } & \multirow{2}{*}{ Sig. } \\
\cline { 2 - 5 } & $\mathrm{B}$ & Std. Error & Beta & & 9.648 \\
\hline (Constant) & 40.377 & 4.185 & & .000 \\
Gender & -2.345 & .631 & -.220 & -3.716 & .608 \\
Age & 1.604 & .175 & .515 & 9.146 & .000 \\
Parental Involvement & -.277 & .061 & -.253 & -4.578 & .000 \\
Community Support & -.650 & .095 & -.360 & -6.841 & .000 \\
Interest in schooling & -.171 & .104 & -.086 & -1.650 & .020 \\
\hline
\end{tabular}

a. Dependent Variable: Academic Redshirting

Table 3 showed the extent to which each of the socio-demographical factors made significant contribution to the prediction of academic redshirting. In term of magnitude of contribution, age made the most significant contribution (Beta $=.515, \mathrm{t}=9.146, \mathrm{p}<0.05$ ); followed by interest in schooling (Beta $=-.086, \mathrm{t}=-1.650, \mathrm{p}<0.05)$, community support $($ Beta $=-.360, \mathrm{t}=-6.841, \mathrm{p}<0.05)$ and parental involvement $($ Beta $=-.253, \mathrm{t}=-4.578, \mathrm{p}<0.05)$ respectively.

Research question IV: Was there any significant difference in the academic redshirting of adolescents with special needs base on their gender? 
Table 4: Table Showing mean, standard deviation, and t-test analysis of the difference between male and female respondents on academic redshirting

\begin{tabular}{lcccccc}
\hline Gender & $\mathrm{N}$ & Mean & Std. Deviation & Df & $\mathrm{T}$ & Sig \\
\hline Male & 75 & 19.0870 & 6.01834 & 148 & 1.353 & .177 \\
Female & 85 & 20.0000 & 4.63600 & & & \\
\hline
\end{tabular}

Table 4 above showed the independent t-test analysis on the difference between in academic redshirting of adolescents with special needs based on their gender. The result demonstrated that the t-value of 1.353 was greater than $p$-value of .177 , at 0.05 level of significance. This implies that there was no significant difference in the academic redshirting of the study participants based on their gender.

\section{Discussion of the Findings}

The result of the first research question revealed that age was the only factor that correlated positively and significantly with the practice of academic redshirting in this study. The positive relationship suggests that an increased influence of age would increase the practice of academic redshirting. While an increased influence of interest in schooling, community support and parental involvement would reduce the practice of academic redshirting based on the perception of adolescents with special needs. This finding agrees with some past studies such as Marshall (2003); Rafoth and Knickelbein (2008); Sarosky (2009): UNICEF (2012); Hen and Goroshit, (2014); Oshima and Domaleski (2016) who found that age was the reason many parents redshirted their children. Their argument is based on the fact that they want to give their wards additional year for maturity. More so, the result further revealed that interest in schooling, community support, and parental involvement related negatively and significantly with academic redshirting. This finding demonstrated that with factors like interest in schooling, community support and parental involvement, academic redshirting may be reduced. This finding uphold the study of Pina, Villalta, Ortiz, Gottschall, Costa, and Weems, (2008); Gottfredson and Hussong (2011); L Fite, Cooley, Williford, Frazer and DiPierro (2014); Smith (2016); Lee and Durksen (2018) who allude that academic redshirting was linked with social, biological and psychological factors.

The second research question indicated that all socio-demographical factors had something to do with the practice of academic redshirting if inclusive education of adolescents with special needs would be achieved. This was found by the total weight pulled by the combined factors in predicting academic redshirting. That is, interest in schooling, parental involvement, community support, age and gender put together significantly affected the practice of academic redshirting based of the perception of adolescents with special needs. This finding substantiates the study of Holbrook (2015) and Elder and Lubotsky (2016) who established that parents that practice redshirting do so for several reasons which include stigmatization, maturity, age, socio-economic status, bullying and academic failure.

Furthermore, the finding from the third research question revealed that age was the most potent factor in this study that was responsible for continuous practice of academic redshirting. This implies that age of individual adolescents with special needs was the main reason they were academically redshirted. While, interest in schooling, parental involvement and community support when developed, enjoyed and recieved, the practice of academic redshirting may perhaps reduce which will pave way for full implementation of inclusive education of individual with special needs.

The last research question on the significant difference in the academic redshirting of adolescents with special needs base on their gender shown that no significant difference was found between male and female adolescents with special needs in being redshirted. Based on this finding, it can be inferred that academic redshirting was not gender sensitive. This finding is supported by 
Huang and Invernizzi (2013); Smith (2016); Capadona (2018) who found that there was no significant different between academically redshirted students' based on gender, ethnicity, economic and disability status. But oppose the study of Databank Child Trends (2014), who found out that that gender was directly linked with academic redshirting of children with special needs.

\section{Conclusion/Implication}

This study concludes that age was the only socio-demographical factor based on the perception of school-going adolescents with special needs that made parents or guidance to practice academic redshirting in Ibadan, Nigeria. While factors such as interest in schooling, community support, parental involvement would discourage such acts when developed, enjoyed and received by individual adolescent with special needs. These findings therefore have implication for advocates of inclusive education, parents, educational psychologists, special educators, curriculum planners, communities, the governments, and educational stakeholders.

\section{Recommendations}

Based on the findings of this study, it was recommended that for inclusive education to be possible and fully implemented, interest in schooling abilities, community support and parental involvement of their children with special needs should be developed and make available to enjoy and receive. Also, parents should in the best interest of their children enroll them into the conventional school at appropriate school age like their counterparts who are not with any special needs so as to initiate their interest in schooling and sense of belonging, by this, full implementation of integrated/inclusive education will be made possible.

\section{Limitations of the Study}

This study is not without shortcomings, one of which is that there are some psychological factors that could also be responsible for the practice of redshirting that were not mentioned in this study. Therefore, factors like stigmatization and self-esteem just to mention a few. Also, unlike this study that only considered adolescents' perception, parent's view of redshirting could equally be explored. However, notwithstanding the limitations of this study, the findings were very adequate and would go a long way in reducing the practice of redshirting so as to achieve inclusive education of individual with special needs. The outcome will also add to scanty empirical literature in the field of educational psychology and special education, and serve as a spring board for future researches.

\section{References}

Adeyemo, David A. 2009. Parental Involvement, Interest in Schooling and School Environment as Predictors of Academic Self-Efficacy among Fresh Secondary School Students in Oyo State, Nigeria. Electronic Journal of Research in Educational Psychology. No 5 - 3 (1), pp. 163-18o.

Ainley, Mary, Suzanne Hidi, and Dagmar Berndorff. "Interest, learning, and the psychological processes that mediate their relationship." Journal of educational psychology 94, no. 3 (2002): 545.

Brandon, Ruth P. 2007. African-American parents: Improving connections with their child's educational environment. Intervention in School and Clinic, 43,116-120.

Capadona, Cassandra R. 2019 "Academically-Redshirted Males' Behavior and Academic Performance at the Middle School Level.

Cook, P. J., Dodge, K. A., Gifford, E. J., \& Schulting, A. B. (2017). A new program to prevent primary school absenteeism: Results of a pilot study in five schools. Children and Youth Services Review, 82, 262-270.

Constantino, Steven M. 2003. Creating a positive school culture by putting research into practice: Engaging all families. Lanham: MD: Rowman and Littlefield Education.

Databank, Child Trends 2014. Early childhood program enrollment.." Retrieved from Learning disabilities. 
Diamond, Karen E., Amy J. Reagan, and Jennifer E. Bandyk 20oo. "Parents' conceptions of kindergarten readiness: Relationships with race, ethnicity, and development." The Journal of Educational Research 94, no. 2, 93-100.

Dixon, Shantina R. 2008 "A study of parental involvement and school climate: Perspective from the middle school." Unpublished doctoral dissertation). Texas A \& M University. College Station, TX. Retrieved from http://repository. tamu. edu/bitstream/handle/1969.1/ETD-TAMU-3070/DIXONDISSERTATION

Education Commission of the States. 2013. Early learning: Kindergarten online database [Data file]. Retrieved from http://www.ecs.org/html/educationissues/kindergarten/kdb_intro_sf.asp

Fite, Paula J., John L. Cooley, Anne Williford, Andrew F, and Moneika DiPierro. 2014 "Parental school involvement as a moderator of the association between peer victimization and academic performance." Children and youth services review 44: 25-32.

Gottfredson, Nisha C., and Andrea M. Hussong 2011. "Parental involvement protects against self-medication behaviors during the high school transition." Addictive behaviors 36, no. 12: 1246-1252.

Graue, Elizabeth M, and James DiPerna 20oo. "Redshirting and early retention: Who gets the" gift of time" and what are its outcomes?." American Educational Research Journal 37, no. 2: 509-534.

Hidi, Suzanne, and K. Ann Renninger 2006. "The four-phase model of interest development." Educational psychologist 41, no. 2: 111-127.

Hidi, Suzanne, K. Ann Renninger, and Andreas Krapp 2004. "Interest, a motivational variable that combines affective and cognitive functioning." In Motivation, emotion, and cognition, pp. 103-130.

Hill, Nancy E., and Lorraine C. Taylor 2004. "Parental school involvement and children's academic achievement: Pragmatics and issues." Current directions in psychological science 13, no. 4: 161-164.

Huang, Francis L., and Marcia A. Invernizzi 2013. "Birthday effects and preschool attendance." Early Childhood Research Quarterly 28, no. 1: 11-23.

Koonce, Danel A., and Walter Harper, Jr 2005. "Engaging African American parents in the schools: A communitybased consultation model." Journal of Educational and Psychological Consultation 16, no. 1-2: 55-74.

Koskel, Ishikawa 2014. Influence of parental involvement on students' academic performance of public mixed day secondary schools in Kuresoi Sub-county, Nakuru County, Kenya. International Journal of Education and Research Vol. 2 No. 12 page 505-516.

Lawrence, K. C. (2019). An investigation of students' awareness of school counselling services in Nigeria between 2017 and 2019. Journal of Gender, Information and Development in Africa (JGIDA), 8(3), 213-227.

Lee, Jihyun, and Tracy L. Durksen 2018. "Dimensions of academic interest among undergraduate students: passion, confidence, aspiration and self-expression." Educational Psychology 38, no. 2 : 120-138.

Mitchell, Mathew 1993. "Situational interest: Its multifaceted structure in the secondary school mathematics classroom." Journal of educational psychology 85, no. 3: 424.

Noel, Andrea M., and Joan Newman 2003. "Why delay kindergarten entry? A qualitative study of mothers' decisions." Early Education and Development 14, no. 4: 479-498.

Oshima, T. C., and Christopher S. Domalesk 2006i. "Academic performance gap between summer-birthday and fall-birthday children in grades K-8." The Journal of Educational Research 99, no. 4: 212-217.

Osisanya, A., Oyewumi, A. M., Adigun O. T. (2015). Perception of parents of children with communication difficulties about inclusive education in Ibadan metropolis. African Journal of Educational Research, 19(1), 2132.

Raffaele Mendez, Linda M., Eun Sook Kim, John Ferron, and Bonnie Woods 2015. "Altering school progression through delayed entry or kindergarten retention: Propensity score analysis of long-term outcomes." The Journal of Educational Research 108, no. 3 (2015): 186-203.

Sansone, Carol, and Jessi L. Smith 20oo. "Interest and self-regulation: The relation between having to and wanting to." In Intrinsic and extrinsic motivation, pp. 341-372. Academic Press.

Sarosky, Adrienne 2009. "Determining whether the age children enter kindergarten affects academic and social development.".

Smith, Christin 2016. "The Effects of Academic Redshirting Among Third-Grade Students in a Rural Southeastern School District."

Zimet, Gregory D., Nancy, Dahlem W, Sara, Zimet G and Gordon, Farley K 1988. "The multidimensional scale of perceived social support." Journal of personality assessment 52, no. 1: 30-41. 